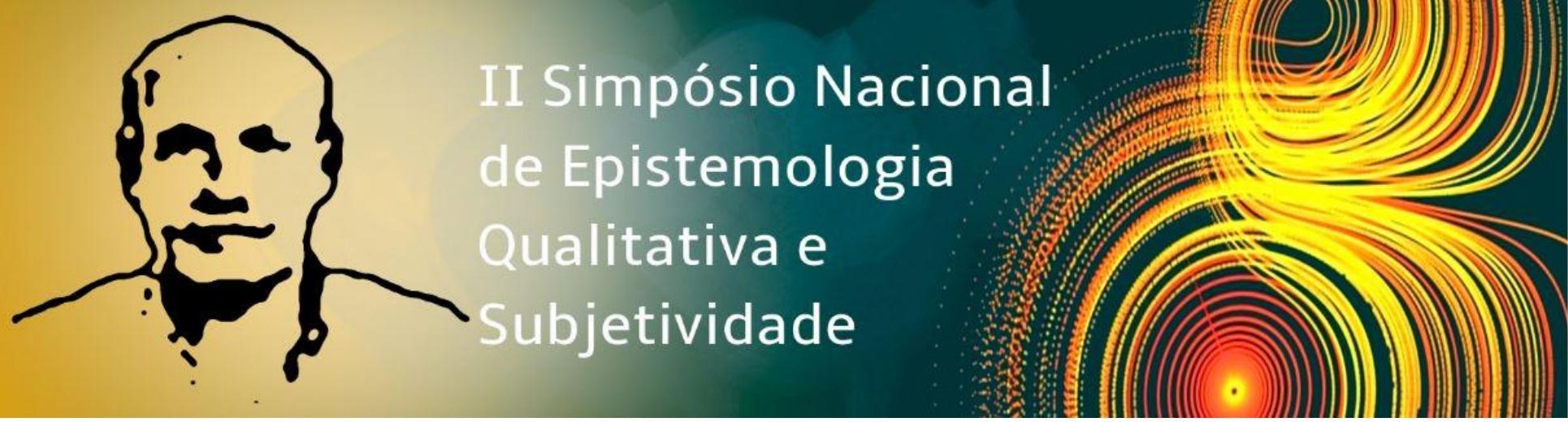

Eixo temático: Subjetividade na formação de professores e outros profissionais

\title{
Momentos iniciais da trajetória docente de uma professora de ciências: uma análise a partir da Teoria da Subjetividade
}

\section{Marciléa Serrão Resque}

Escola de Ensino Fundamental e Médio "Tenente Rêgo Barros"

serraomarcilea@gmail.com

\section{Resumo}

Apresentamos, no presente artigo, um recorte de uma pesquisa de doutorado em andamento, na qual objetivamos compreender as configurações de sentidos subjetivos de uma professora de ciências sobre suas opções pela docência e seus primeiros anos de atuação profissional. Analisamos as informações a partir de uma perspectiva histórico-cultural da subjetividade, apoiados na epistemologia qualitativa, que enfatiza o caráter construtivo-interpretativo e dialógico da pesquisa. Realizamos um estudo de caso a partir de informações obtidas por meio de complemento de frases, questionário aberto e entrevista individual. Os resultados mostram que as configurações de sentidos subjetivos, dos momentos iniciais do percurso profissional da professora, estão profundamente enlaçadas às suas interações sociais, nos diferentes contextos em que transitou, desde a infância. O referencial adotado possibilitou dar visibilidade ao sujeito concreto, em sua trajetória singular, o que costuma ser desconsiderado nas generalizações que resultam de uma abordagem do percurso docente por ciclos.

Palavras chave: Configuração subjetiva, Trajetória profissional docente, Sentido subjetivo, Subjetividade.

\section{Os momentos Iniciais da trajetória docente e a Teoria da Subjetividade}

Quais motivações estão envolvidas nas opções pela docência em ciências? Como os professores percorrem os seus primeiros anos na profissão? No presente artigo, iremos apresentar um estudo qualitativo sobre esses dois momentos iniciais da trajetória profissional de uma professora de ciências, compreendidos a partir da perspectiva histórico-cultural da subjetividade. De acordo com Castro (2009), as discussões que giram em torno da vida dos professores, correspondem a uma das principais temáticas de análise sobre os profissionais da educação, em virtude das preocupações com os processos de formação docente em meio aos desafios do cenário educativo contemporâneo. Desta forma, as questões que constituem e circundam a trajetória profissional docente têm ocupado muitas pesquisas na área da educação. 


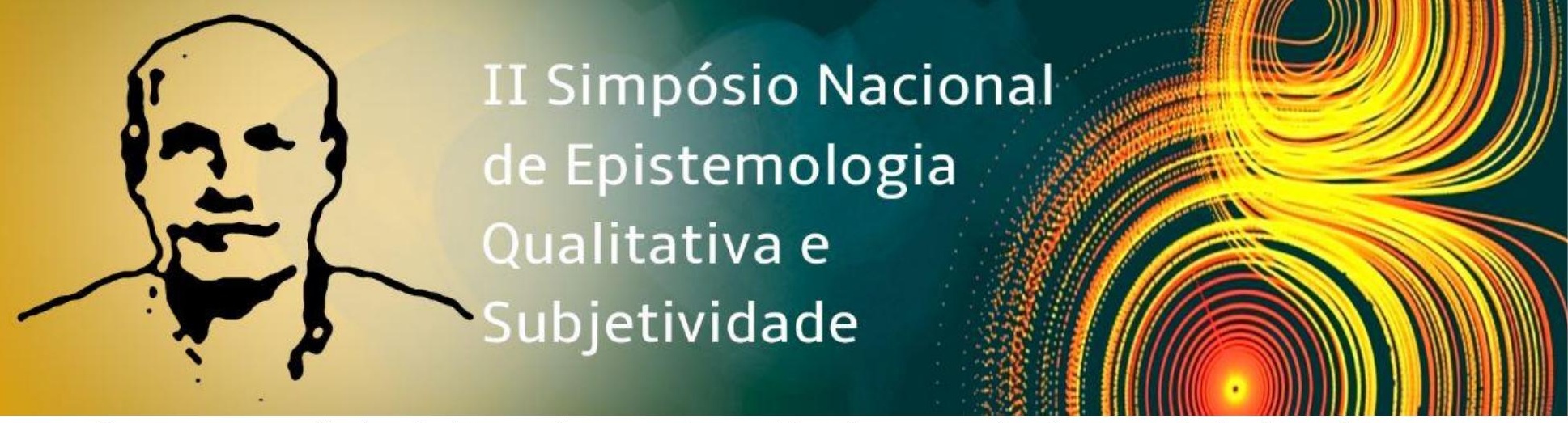

O percurso profissional dos professores é considerado como abordagem aglutinadora de questões que envolvem a formação da identidade docente, saberes profissionais, modelos de profissionalização e desenvolvimento pessoal dos professores. É neste contexto que os estudos sobre as trajetórias docentes se inserem, possibilitando compreender as diferentes interações entre os aspectos pessoais, sociais e profissionais, que são construídos no decorrer do percurso dos professores.

Para Huberman (2000, p. 37), a trajetória profissional docente pode ser enfocada na perspectiva clássica de carreira, da qual podem ser destacadas "sequências" ou "maxiciclos", que segundo o autor, seriam acontecimentos que poderiam ser vivenciados por "um grande número, por vezes pela maioria dos elementos de uma população estudada". Tais estudos propõem "tendências centrais", eventos e características que poderiam estar presentes no percurso profissional docente.

Nesta compreensão, os primeiros anos corresponderiam às fases de entrada na carreira $e$ de estabilização. A primeira condiz com os primeiros dois ou três anos de ensino e seria caracterizada pelo período em que os professores apresentariam tanto um entusiasmo inicial em começar uma nova etapa de vida, agora profissional, quanto ao "choque do real", que corresponderia ao contato com a complexa realidade da docência, muitas vezes diferentes daquelas vividas ou idealizadas pelos professores quando ainda eram estudantes de graduação. Já a estabilização, corresponderia aos oito a dez anos seguintes na profissão docente. O sentimento de pertencimento a um grupo profissional, assim como a conquista de um estilo próprio de ensino e maior flexibilidade e tolerância frente às adversidades da prática docente, seriam aspectos recorrentes nesta etapa (HUBERMAN, 2000).

Os estudos desenvolvidos por Huberman (2000) inspiraram muitas outras pesquisas na área da educação e também no campo das ciências naturais. Nestes escritos, as trajetórias docentes são ressaltadas para discutir a construção da identidade docente nos cursos de formação inicial ou continuada, a configuração de saberes profissionais, a permanência dos professores na carreira, entre outros temas. Com esta perspectiva, aparece nos trabalhos tanto a concepção de professor como sujeito universal, sem que suas singularidades sejam realçadas nas pesquisas, quanto de professores compreendidos como sujeitos concretos e históricos, portadores de emoções e com histórias de docência singulares.

Faustino (2011, p.1) menciona que as investigações produzidas no âmbito desta temática têm contribuído para por em relevo dimensões da profissão e dos professores que até então ficavam secundarizadas nas propostas de pesquisa, "trazendo à luz a pluralidade de aspectos que até pouco tempo eram desconhecidos". A autora sublinha ainda que a partir desta perspectiva muitas outras questões sobre os professores e outros aspectos da docência vêm sendo discutidos.

Pretendemos contribuir para a construção de novas formas de olhar para estas etapas da formação dos professores, que classicamente têm sido estudadas no âmbito das pesquisas sobre ciclos de vida docente (FAUSTINO, 2011). Ao falar sobre tais pesquisas, Marchesi (2008, p. 33) argumenta que "a grande maioria dos estudos sobre os professores se refere à categoria como grupo bastante coeso e com atitudes e traços similares". 


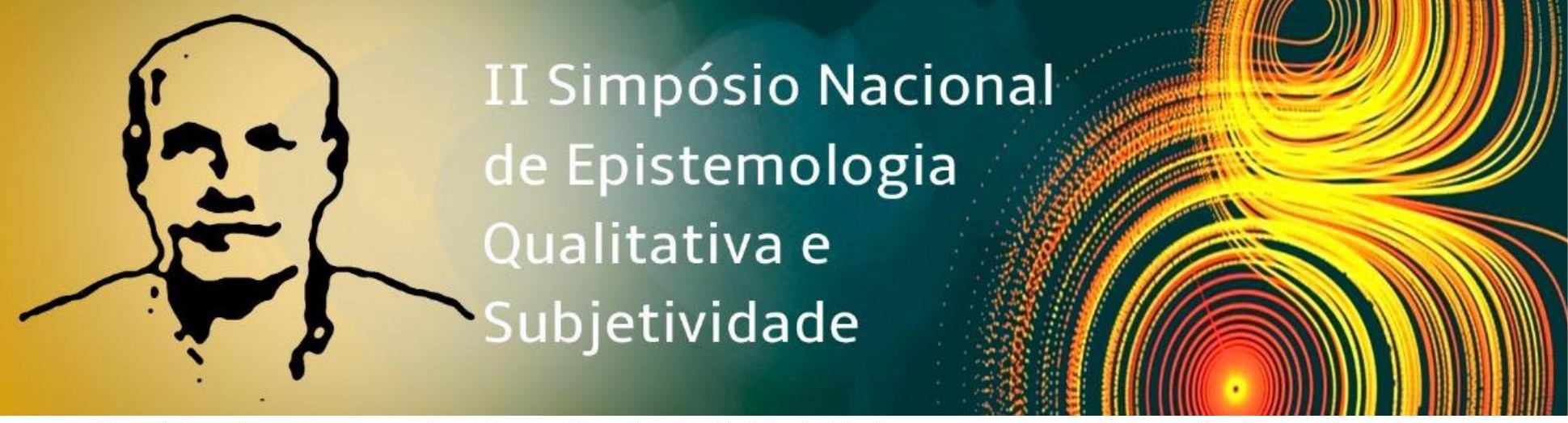

Caminhando em outra direção, a Teoria da Subjetividade proposta por Fernando González Rey (2005) assenta sua opção pelo sujeito concreto, "indissociável da vivência de suas emoções, da construção de sua história, de suas relações sociais, de sua inserção na cultura e de sua maneira de construir sentidos sobre si e o mundo" (NEUBERN, 2009, p. 305).

Ao compreender estas etapas da vida profissional docente à luz da Teoria da Subjetividade, reconhecemos a dimensão eminentemente ativa e criativa dos sujeitos, que empreendem modos de compreensão próprios e singulares nas diferentes atividades que vivenciam e desempenham. Na concepção de González Rey

a ideia de sujeito recupera o caráter dialético e complexo do homem, de um homem que de forma simultânea representa uma singularidade e um ser social, relação esta que não é de determinação externa, mas uma relação recursiva em que cada um está simultaneamente implicado na configuração plurideterminada dentro da qual se manifesta a ação do outro (GONZÁLEZ REY, 2003, p. 224).

Esta visão se contrapõe à concepção uniformizadora de sujeito epistêmico, que dotado e guiado preponderantemente pela razão, apresenta qualidades universais e idênticas (LIMA, 2002). Neste horizonte teórico, a subjetividade delineia outras formas de compreensão do sujeito, considerando que suas singularidades são construídas a partir dos múltiplos sentidos que cria em sua vida social.

A categoria de sentido subjetivo assume especial importância para a discussão da subjetividade sob o marco histórico- cultural. Nessa concepção teórica, tal categoria "integra o emocional a processos de significação e ressignificação simbólica, que passam a ser compreendidos como expressões da subjetividade enquanto sistema" (ALMEIDA; MARTINEZ, 2014, p. 727). Os sentidos subjetivos corresponderiam, nesta ótica, a construções complexas de sujeitos com histórias e realidades singulares, que subjetivam o mundo simbólico e emocionalmente, indo muito além da simples influência linear e direta de outros sistemas da realidade (GONZÁLEZ REY, 2005, p. 22). Já a categoria configurações subjetivas, representariam às integrações, de forma sistêmica e flexível, dos sentidos subjetivos produzidos pelos sujeitos nos diferentes tempos e espaços de sua vida pessoal e profissional.

Assumir esse entendimento de subjetividade para discutir as decisões em seguir a carreira docente e os primeiros anos de atividade pedagógica, implica trazer para discussão, os diferentes cenários de formação pessoal e profissional do professor como sujeito social e historicamente constituído. Com esta perspectiva, assumimos que os caminhos profissionais são vividos por sujeitos concretos e se expressam em configurações subjetivas complexas, que são construídas a partir do intercâmbio que se processa entre os professores e o cenário social e histórico que tomam parte (NEUBERN, 2009).

A teoria da subjetividade possibilita discutir a complexa trama de sentidos subjetivos envolvidos nestes momentos importantes da formação docente, que correspondem à opção pela docência em ciências e aos anos iniciais na profissão. Significa assumir que as emoções, os valores, as expectativas, os sonhos, a história pessoal e de formação, assim como, a realidade de trabalho destes professores são dimensões indissociáveis. Desta forma, não corremos o risco de simplificar a compreensão da trajetória dos professores, ora entendendo

\section{BRASÍLIA, 22 a 25 DE OUTUBRO DE 2019 CENTRO UNIVERSITÁRIO DE BRASÍLIA - UNICEUB}




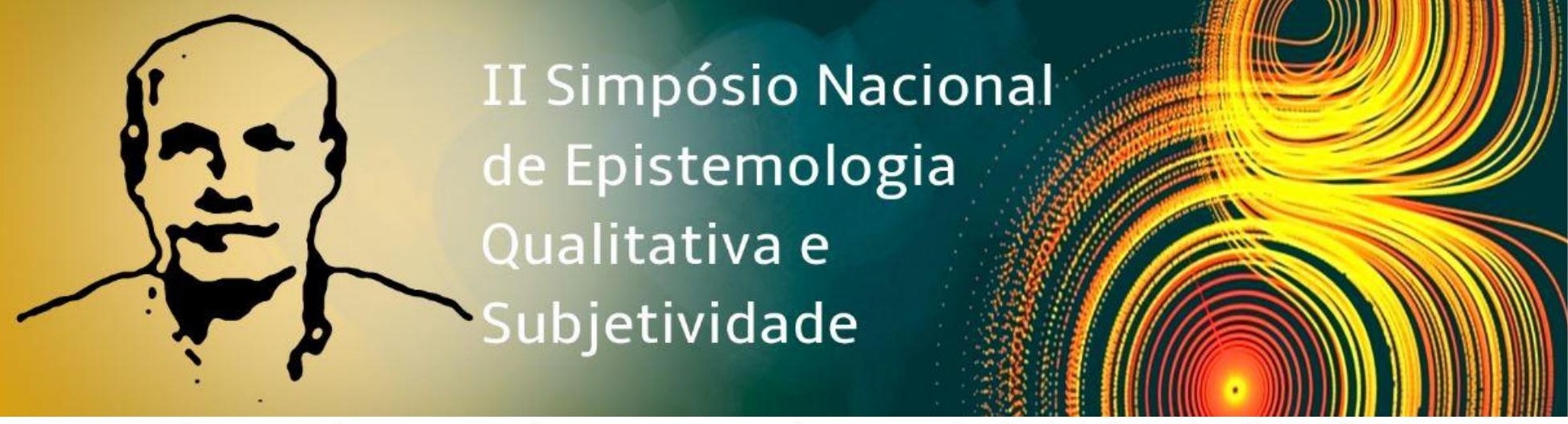

como decorrente de aspectos eminentemente pessoais, ora em virtude de influências diretas do meio social.

Optamos, portanto, por outros caminhos teóricos para compreender os momentos da trajetória docente. Ao adotar a Teoria da Subjetividade para discutir as questões que envolvem as opções pela docência e os primeiros anos como professora de ciências, pretendemos deslocar as análises para a relação dialética que o sujeito historicamente situado estabelece com o meio social do qual participa.

Assim, nosso objetivo no presente estudo é compreender como se configuram para uma professora de ciências, os sentidos subjetivos da docência nos momentos de opção e nos primeiros anos de sua vida profissional.

\section{Metodologia}

Optamos pelo percurso investigativo de natureza qualitativa. Utilizamos como principal diretriz a Epistemologia Qualitativa, desenvolvida por González Rey (2005). A partir deste referencial, compreendemos a pesquisa como processo de comunicação e diálogo entre os envolvidos no processo investigativo. Valorizamos os casos singulares como instâncias legítimas de produção de conhecimentos. Assumimos o caráter eminentemente interpretativo das informações produzidas. Desta forma, a Epistemologia Qualitativa confere "valor ao conhecimento não por sua correspondência imediata e linear com o real" (GONZÁLEZ REY, 2005, p. 6), mas pela capacidade de produzir novas formas de conhecimento e ação sobre a realidade. Neste artigo, são as opções e os momentos iniciais do percurso docente de uma professora de ciências que passaremos a chamar de Deise que serão analisadas.

Para produzir as informações utilizamos três instrumentos: um questionário aberto (QA), com quatro perguntas gerais sobre a temática; um complemento de frases (CF), composto de 38 indutores a serem concluídos pela professora e uma entrevista $(E N)$ que desenvolvemos sobre suas opções e seus primeiros anos na profissão. De posse das informações construídas, realizamos uma análise interpretativa dos sentidos subjetivos de docência para a professora, a partir de indicadores que identificamos em suas expressões aos diferentes instrumentos e procuramos compreender como se organizavam tais sentidos subjetivos em cada um dos momentos de sua trajetória profissional.

\section{Apresentando a professora Deise}

Nascida em uma cidade do interior do Pará, a professora Deise teve uma história atravessada por muitas adversidades, mas também por grandes momentos de superação. Oriunda de uma grande família, que ela define como "resiliência pura" (Deise - CF) em que sua mãe e avós eram trabalhadores rurais, Deise também teve que trabalhar em sua infância e adolescência nas lavouras de pimenta do reino para ajudar sua mãe no sustento da família. Mudou-se para a capital aos treze anos de idade para continuar seus estudos e assim precocemente ela se separou de sua mãe, avós e irmãos.

Dito isto, passamos então às analises interpretativas sobre os sentidos subjetivos produzidos sobre estes momentos da história de vida profissional da professora Deise e à composição de suas configurações subjetivas.

\section{BRASÍLIA, 22 a 25 DE OUTUBRO DE 2019 CENTRO UNIVERSITÁRIO DE BRASÍLIA - UNICEUB}




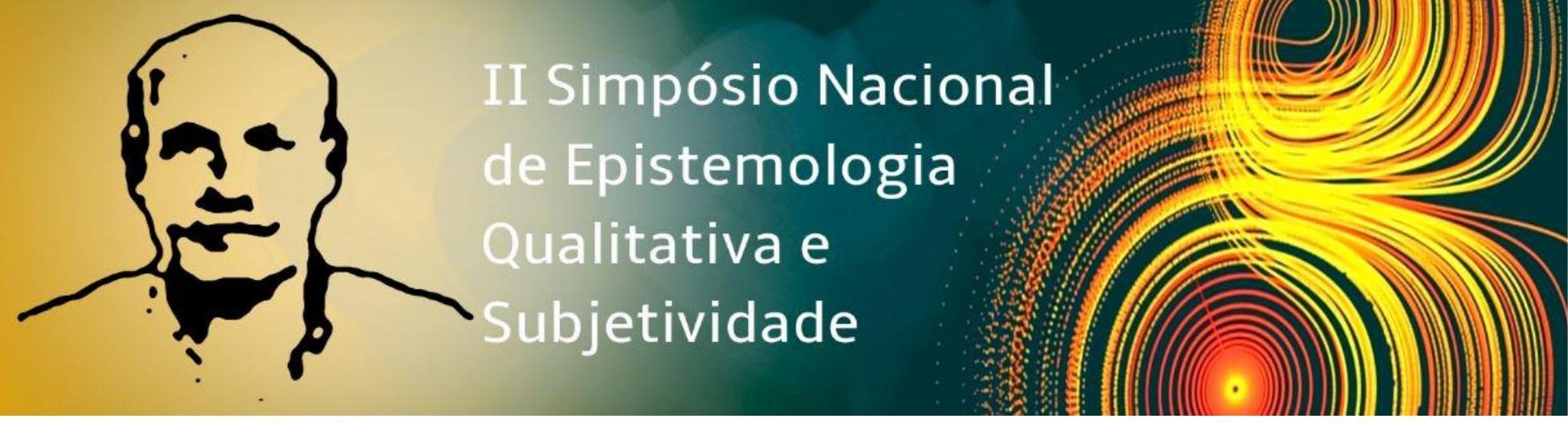

prover sua família. Portanto, seu incentivo para que ela seguisse como professora foi importante para ela naquele momento de tomada de decisão em direção à profissão docente.

Admiração pelos seus professores de ciências e biologia que materializavam sua imagem de bons profissionais: Ela expressou que as referências de professores que considerava como modelos de profissionais também influenciaram na escolha de seu curso. Ela manifestou que "depois quando fui prestar vestibular, a escolha do curso? Culpa dos meus professores de ciências naturais, na $7^{\mathrm{a}}$ série e da minha professora de biologia no ensino médio, eles eram dois espetáculos de professores! Queria ser como eles, (pensava) um dia chego lá!" (Deise QA). Diante da história de vida profissional de Deise, podemos compreender que este sentido subjetivo, foi construído a partir da profunda admiração que sentia por seus professores, desde o ensino fundamental até o nível médio. Admiração que tinha como base a consideração de que eles eram modelos de bons profissionais e exemplos a serem seguidos por ela.

Desejo de mudar as condições sociais de sua família: Outro sentido subjetivo de docência relativo a este momento refere-se ao desejo de mudança de suas condições sociais iniciais. Como moradora do interior e filha de agricultores, a profissão de professora se revelava socialmente melhor posicionada do que a exercida por seus pais e uma forma de "evoluir sempre" (Deise - CF), ir além do que seus pais foram. Nesta linha, ao decidir seguir a docência em ciências, este sentido se articulou aos outros que Deise construiu em seu caminho de vida. No horizonte da Teoria da Subjetividade, as "experiências, significados e sentidos de procedências diferentes perdem sua localização no tempo e no espaço" (GONZÁLEZ REY, 2003, p. 220).

\section{$O$ inicio da carreira docente}

A trajetória docente de Deise iniciou quando ela ainda era aluna da graduação de Ciências Biológicas. Ainda na universidade, como aluna de um curso de licenciatura, Deise comentou que tinha clareza que a graduação que cursava destinava-se a formar professores de ciências e biologia, contudo expressou que naquele momento "nunca me percebi como futura professora! Estudava e sabia que era pra ser professora, mas não fazia ideia do que me esperava" (Deise - QA).

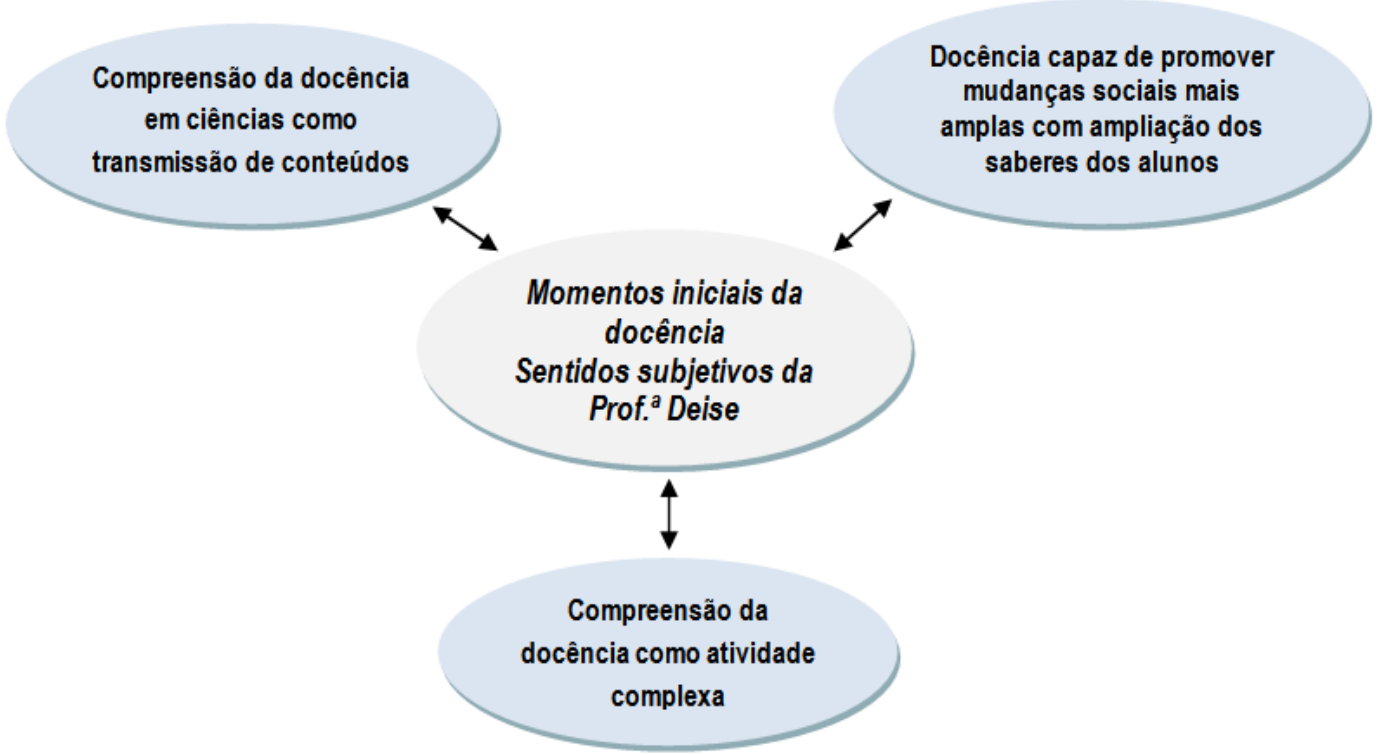




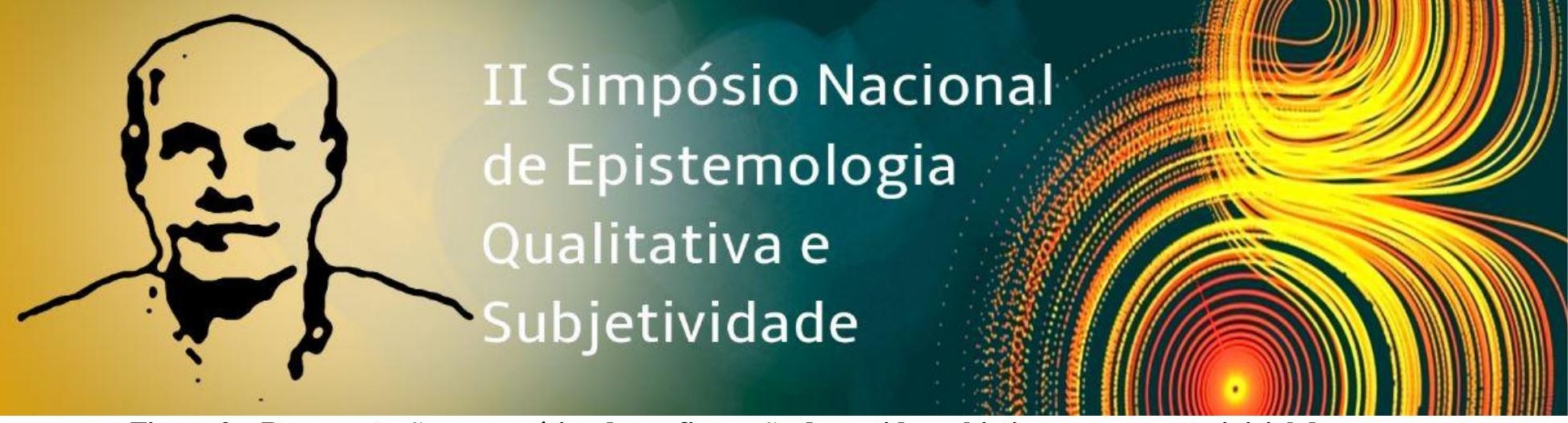

Figura 2 - Representação esquemática da configuração de sentidos subjetivos no momento inicial da trajetória docente da professora Deise.

Compreensão da docência em ciências como transmissão de conteúdos: Na época em que a professora ingressou no curso de Licenciatura em Ciências Biológicas, ele estava estruturado no chamado modelo "três mais um". Para autores como Carvalho \& Gil Perez (2003), os cursos refletiam o modelo conteudista de ensino e reforçavam a concepção simplista de ensino de ciências, fundamentada na visão de que, para ensinar bastava ter domínio dos saberes específicos da disciplina. Estas eram ideias que circulavam com muita intensidade no universo acadêmico em que a professora Deise transitava. O valor dado ao conhecimento científico refletido pelo lugar de destaque ocupado na organização da estrutura pedagógica do curso, produziu ressonâncias em sua compreensão de docência em ciências. Deise comentou que "na época da graduação... estagiava no laboratório de neurociências, mesmo sabendo que não ia ser pesquisadora" (Deise - CF), "quase todos os alunos queriam ser pesquisadores" (Deise - QA). Ao completar a frase "no início da minha docência.... antes eu achava que tinha que explicar os conteúdos e, os alunos tinham que estudar", e que queria ser uma professora de ciências capaz de "provocar mudança comportamental no cérebro do meu aluno, levando-o a crer que ele é capaz de compreender e assim, aprender qualquer coisa" (Deise - QA). Assim, nestes momentos iniciais, a professora construía sentidos que relacionavam sua docência à comunicação de saberes científicos, e a promoção do desenvolvimento intelectual de seus alunos.

Docência capaz de promover mudanças sociais mais amplas com ampliação dos saberes dos alunos: Mas outros sentidos também transitavam em suas configurações subjetivas, associados aos ideais de mudanças sociais, de uma docência capaz de modificar a vida dos alunos e mudar o mundo. Expressa que "no passado... pensava que, sendo professora poderia melhorar o mundo" (Deise - CF) e que o conhecimento científico seria uma poderosa ferramenta de transformação, assim ela desejava "ensinar ciências e biologia para... melhorar o mundo" (Deise - CF). Mesmo que aparentemente distantes ou até mesmo inconciliáveis, estes sentidos de docência como comunicação de saberes e capaz de modificar a vida dos alunos, estavam relacionados ao valor que a professora atribuía ao estudo, como forma de desenvolvimento pessoal e mudança de vida. Nesta linha, os sentidos de docência de Deise foram construídos a partir do que ela própria experimentou e valorizou em sua trajetória de vida como filha de trabalhadores rurais, como aluna que teve que mudar de cidade para continuar estudando, como estagiária que se viu de frente com a realidade burocrática e complexa das escolas e também como professora recém formada que acalentava, como ela mesma expressa, "um sonho... de mudar o mundo com a minha docência" (Deise - CF). Os sentidos subjetivos, como categoria desenvolvida por González Rey (2003), enunciam como os diferentes processos sociais e individuais são configurados na experiência da pessoa.

Compreensão da docência como atividade complexa: $O$ encontro com a complexidade da docência ocorreu ainda no transcurso da graduação, "só comecei a perceber o mosaico que é ser professor, filosoficamente falando, quando fiz a [disciplina] introdução à educação" (Deise - QA). Deise expressou que as leituras e discussões realizadas na disciplina a fizeram perceber que existiam questões muito mais amplas e profundas envolvidas na ação dos professores, essa "era só a ponta do iceberg" (Deise - QA). Comentou ainda que as 


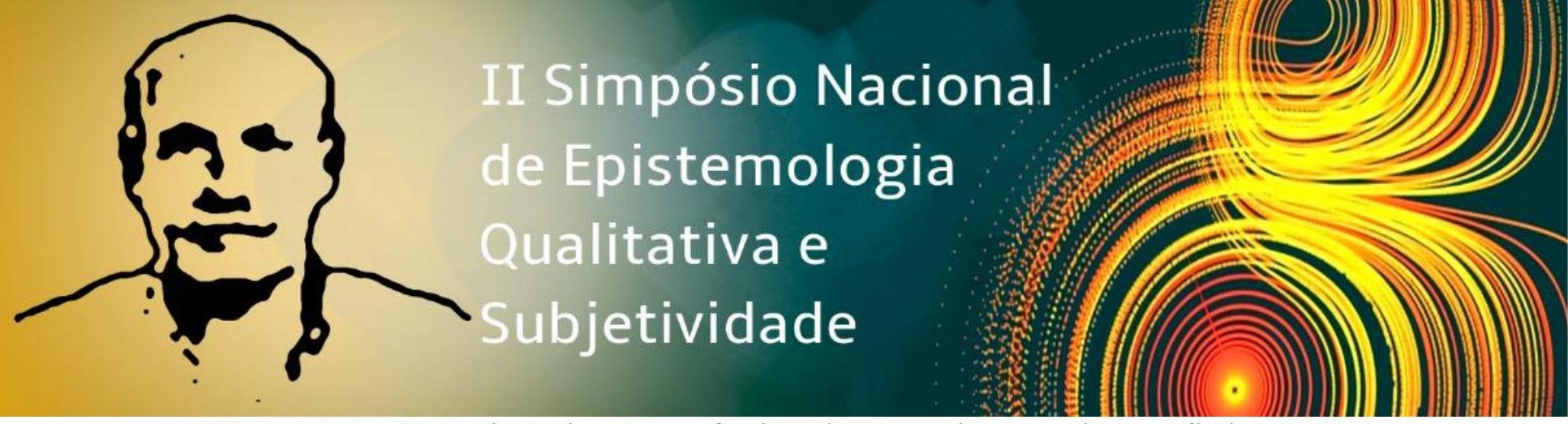

FAUSTINO. I. M. L. R. Trajectorias de professionalidade e ciclo de vida profissional: Um contributo para o conhecimento dos professores de educação especial. 2011. 260 f. Dissertação (Mestrado em Ciências da Educação) - Escola Superior de Educação de Lisboa, Lisboa, 2011.

GONZÁLEZ REY, F. L. Sujeito e subjetividade: uma aproximação histórico-cultural. São Paulo: Pioneira Thomson Learning, 2003.

Thomson Learning, 2005. . (Orgs.). Subjetividade, Complexidade e Pesquisa em Psicologia.

HUBERMAN, M. O ciclo de vida profissional dos professores. In: NÓVOA, A. (Org.). Vidas de professores. $2^{\mathrm{a}}$ ed. Porto: Porto, 2000. p. 31-61.

LIMA, J. F. L. O sujeito, a racionalidade e o discurso pedagógico da modernidade. Interações.V. 7, n. 14, 2002, p. 59-84.

MARCHESI, A. O bem-estar dos professores: competências, emoções e valores. São Paulo: Artmed, 2008

NEUBERN, M. da S. Hipnose, dor e subjetividade: considerações teóricas e clínicas. Psicologia em Estudo, Maringá, v. 14, n. 2, 2009, p. 303-310. 